\title{
Dominant role of temperature on deep earthquake mechanics for the Tonga slab near the bottom of the upper mantle
}

\author{
Satoshi Kaneshima ${ }^{*}$ and Shoichi Yoshioka ${ }^{2}$
}

\begin{abstract}
The effects of temperature on the mechanics of deep earthquakes are investigated based on detailed seismic images of a horizontal portion of the Tonga slab $\left(19^{\circ} \mathrm{S}\right.$ to $\left.22^{\circ} \mathrm{S}\right)$. The hypocenter distribution of deep earthquakes and tomographic models have shown that the Tonga slab in this region stagnates laterally around the upper- and lower-mantle boundary. We analyze data from seismic networks in the United States and Japan from the deepest earthquakes that occurred in the stagnating part of the slab (focal depths 658 to $678 \mathrm{~km}$ ). We observe a clear arrival approximately $8 \mathrm{~s}$ after the direct $P$ wave and find that it is an S-to-P converted wave emitted upward from the deepest earthquake foci and reflected downward by a horizontal interface located nearly $30 \mathrm{~km}$ above the foci. The $S$ wave speed drops upward across the interface by a few percent, so the interface is best interpreted as the former oceanic Moho in the stagnating Tonga slab. A numerical model of the thermal structure of the Tonga slab is constructed based upon the slab geometry, with the dynamics of the slab motion being incorporated. We find that if the deepest earthquakes occur in the coldest part of the slab, the vertical distance between the foci and the Moho should be approximately $30 \mathrm{~km}$, which agrees well with the observations. The temperature around the foci is determined to be $750^{\circ} \mathrm{C}$. We suggest that deep earthquakes are stringently restricted below this temperature, near the bottom of the upper mantle.
\end{abstract}

Keywords: Tonga slab; Deep earthquakes; Limiting temperature; Former oceanic Moho; Array analyses; Converted waves

\section{Findings}

\section{Introduction}

The overall features of slab subduction are now well known, owing to advances in seismic tomography and dynamic modeling. However, the detailed mechanism of slab descent across the upper- and lower-mantle boundary still needs to be constrained, as important geophysical issues such as deep earthquake mechanics and the fate of oceanic crust hinge upon it.

The thermal control on deep earthquake mechanics has been suggested by previous researchers (e.g., Gorbatov and Kostoglodov 1997; Wiens 2001). Wiens (2001) shows that the colder a slab is, the more deep earthquake aftershocks tend to occur in the slab. Gorbatov and

\footnotetext{
${ }^{*}$ Correspondence: kane@geo.kyushu-u.ac.jp

1 Department of Earth and Planetary Sciences, Faculty of Science, Kyushu

University, Hakozaki, Higashi-ku, Fukuoka 812-8581, Japan

Full list of author information is available at the end of the article
}

Kostoglodov (1997) show positive correlation between the maximum depths of deep seismicity and the thermal parameters of slabs (the product of the age and downward velocity of the slab, called ' $\Phi$ ' hereafter). We note that it is by no means straightforward to reveal the accurate thermal structures of deep slabs around deep earthquake foci and that previous studies relying mostly on global seismicity data sets and utilizing $\Phi$ of deep slabs have a weakness in this respect. A more recent study by Emmerson and McKenzie (2007) re-examines the thermal structure of individual slabs and compares the temperature structure with the deep seismicity for each slab. These authors then estimate the limiting temperature, below which deep earthquakes can occur. However, it is implicitly assumed that the hypocenters of the deepest earthquakes occur in the coldest part of the slabs, which needs to be verified. It, thus, remains a challenge to accurately constrain the locations of hypocenters of the deepest earthquakes

\section{Springer}

(c) 2014 Kaneshima and Yoshioka; licensee Springer. This is an Open Access article distributed under the terms of the Creative Commons Attribution License (http://creativecommons.org/licenses/by/4.0), which permits unrestricted use, distribution, and reproduction in any medium, provided the original work is properly credited. 
inside the slabs for a better understanding of the thermal control on deep earthquake mechanics. An advantage of this study over previous global studies is that accurate observational constraints are available for the hypocenters within the Tonga slab. A recent study by Kubo et al. (2009) has determined the temperature near the deep earthquake foci inside the Mariana slab, around $600 \mathrm{~km}$ depth, to be about $550^{\circ} \mathrm{C}$ based upon the observation of a metastable olivine wedge (Kaneshima et al. 2007). However, experimental studies on the condition below which metastable olivine persists still carry substantial uncertainty. In this study, we investigate the role of thermal structure with unprecedented resolution on the basis of the geometry of the Tonga slab and the hypocenter distribution in it. We shall focus on the problem of whether deep earthquakes can occur under certain temperature and stress conditions and shall not discuss specific processes in which slab rocks rupture during deep earthquakes. The results show a very stringent thermal constraint on deep earthquake mechanics near the bottom of the upper mantle.

Our arguments rely critically on seismological detection of former oceanic crust. It has been debated whether the crust is scraped off near the upper- and lower-mantle boundary and remains in the upper mantle or if it continues subducting into the lower mantle, being attached to the slab (e.g., Karato 1997), while studies of scattered seismic waves have confirmed the ubiquitous presence of compositional heterogeneities that are most likely to represent rocks with basaltic composition in the mid-lower mantle (e.g., Kaneshima and Helffrich 1999, 2010). As for the shallower upper mantle (depths of 50 to $350 \mathrm{~km}$ ), a thin oceanic crust with lower seismic speeds has been detected by ScSp analyses (e.g., Nakanishi 1980; Helffrich et al. 1989). Intact subduction of oceanic crust deeper in the upper mantle has not been confirmed by seismic observations but is often assumed in many geophysical and geochemical studies. This is partly because there is no obvious mechanism in the upper mantle to strip the crust from the slab. Thus, it has been an important challenge for seismologists to detect former oceanic crust attached to the slab, if any, deeper in the mantle. In this study, we first present seismological evidence that shows the attachment of former oceanic crust to the underlying peridotitic slab at the bottom of the upper mantle. This observation suggests that the boundary (which shall be called the former oceanic Moho or simply Moho) remains sharp during the descent through the upper mantle.

\section{Event locations and regional deep seismicity}

We focus on a small area in the Tonga subduction zone at latitudes from $19^{\circ} \mathrm{S}$ to $22^{\circ} \mathrm{S}$, where detailed structure of the slab has been imaged by the accumulation of long-term array data. The data we used are short-period seismograms from the University of Washington network (UW),

\section{a}

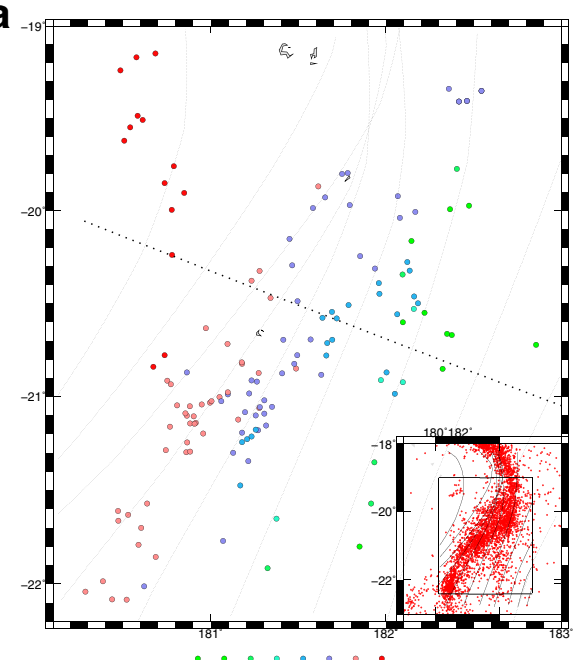

30040050000000 km

b

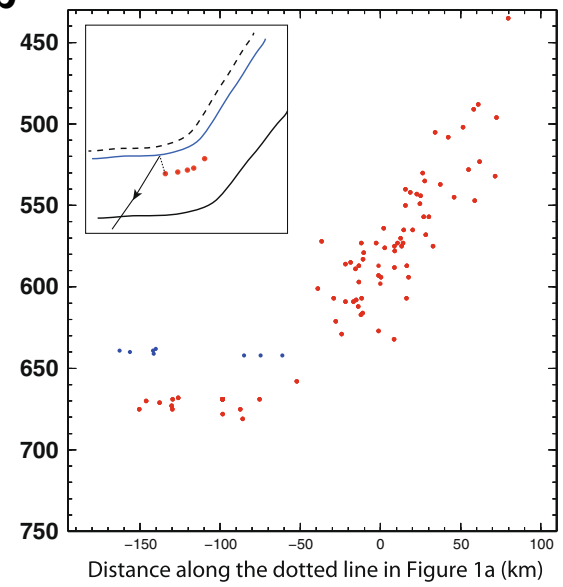

Figure 1 Event locations and geometry of the slab. (a) Map of the Tonga region showing the relocated epicenters of the events (circles, Table 1), with focal depths shown with a color scale. Thick dotted line is approximately parallel to the subduction direction, along which the vertical cross section of hypocenters and reflection points is shown. Contours of the depths of the Tonga slab are shown every $50 \mathrm{~km}$ from 250 to $700 \mathrm{~km}$ with thin dotted line (Gudmundsson and Sambridge 1998). Plotted here and in the cross section (b) are essentially all the events large enough to be relocated accurately by incorporating array measurements of pP. (Inset) PDE epicenters of the deep and intermediate-depth earthquakes from 1970 to 2013 (deeper than $600 \mathrm{~km}$, all magnitudes) are shown with red dots in a map of the larger area of the Tonga subduction zone. The study area is shown in the box in the middle. Gray irregular shapes are the islands of Fiji. (b) Vertical cross section of the relocated hypocenters and conversion (reflection) points along the thick dotted line in (a). The horizontal axis indicates the distance along the dotted line from the origin taken at $20.5^{\circ}, 181.5^{\circ} \mathrm{E}$, WNW to ESE from left to right. Red circles show the hypocenters of the deep events, while blue circles show the locations of the reflection points corresponding to the $X$ phase (interpreted as the Moho). (Inset) Schematic figure of the Tonga slab showing hypocenters (red circles), former Moho (blue line), crust, and ray path of s-to-P waves (dotted line for $\mathrm{S}$, and solid line with arrowhead for P). Dashed line shows the boundary between the former oceanic crust and the surrounding mantle. 
J-array (JA), and Hi-net (HI) in Japan for very deep earthquakes $(658 \mathrm{~km} \leq h \leq 678 \mathrm{~km}$ ) that occurred at the Tonga subduction zone (Figure 1a) from 1995 to 2009 (Table 1). We relocate the earthquakes using arrival times of $\mathrm{P}, \mathrm{PKP}$, and $\mathrm{S}$ waves reported by the ISC using the method described in Kaneshima et al. (2012). In order to constrain the focal depths, we use pP-P times measured for the UW array by slant stacking the seismograms with the slowness predicted for the pP wave.

The relocated hypocenter distribution of the events, combined with those of shallower events (Figure 1b), shows that the Tonga slab descends from ESE to WNW. The events near the northwestern edge of the study area with focal depths $668 \pm 10 \mathrm{~km}$ are hereafter called either 'deepest earthquakes' or 'deepest events' in this study. There are 14 deepest events $\left(m_{b}>5\right)$ since 1995 , whose hypocenters are well constrained (Table 1 ). The cluster of deepest events extends nearly laterally for about $100 \mathrm{~km}$ (Figure 1b). The frequent occurrence of deepest earthquakes sharply terminates beyond the northwestern edge of the study area (Figure 1a, inset). If the horizontally lying slab really exists further to the northwest, as suggested by tomography models, the rapid truncation of seismicity should reflect a change in the thermal and/or material conditions of the slab. It is believed that deep earthquakes do not occur after the post-spinel transformation because of significant grain size reduction due to the phase transformation. In the present case, the transition from seismic to aseismic conditions inside the slab does occur not vertically as usual, but laterally, and the post-spinel transformation front is probably located somewhat below the foci (Kaneshima et al. 2012). Therefore, the transition is most likely to reflect thermal effects.

\section{Waveform data and detection of former oceanic Moho by array analyses}

We use array techniques to detect later arrivals in the $\mathrm{P}$ coda, which are converted and/or reflected at an approximately horizontal interface around the focal depth. The data processing methods are the same as in Kaneshima et al. (2012). We find anomalous arrivals that are not predicted by the standard seismological Earth models such as ak135 (Kennett et al. 1995), approximately $8 \mathrm{~s}$ after the direct $\mathrm{P}$ waves (hereafter called ' $\mathrm{X}$ phase'). The measured slowness of these arrivals relative to $\mathrm{P}$ are mostly positive $\left(\Delta \mathrm{p} \sim+0.02 \mathrm{~s} /{ }^{\circ}\right)$ (Figure 2, Table 2). This means that the $\mathrm{X}$ phase is not an S-to-P converted wave (emitted downward from the foci as an $S$ wave) generated at the ' 660 $\mathrm{km}$ discontinuity' that is depressed below the foci down to about $680-\mathrm{km}$ depth but is an s-to-P wave that is emitted upward as an $\mathrm{S}$ wave and reflected at an interface above the foci at a depth of about $640 \mathrm{~km}$ (Table 2). This inference is supported by a positive correlation between the focal depth and the arrival times of the $\mathrm{X}$ phase relative to $\mathrm{P}(\Delta \mathrm{t})$ among the deepest events observed at Hi-net (Table 2, Figure 3). The reflection points are determined using the measured $\Delta \mathrm{t}$ and the hypocentral locations, based on the assumption that the s-to-P reflection occurs at a horizontal interface. The averaged vertical distance of the conversion point from the foci are about $30 \mathrm{~km}$ when ak135 is used (Figure 1b, Table 2), and the correction for a $4 \%$ higher speed along the path inside the slab to the reflection points (e.g., Deal et al. 1999) decreases the interface depth by less than $2 \mathrm{~km}$.

For events EV8, EV9, and EV10 (Table 1), the stacked waveforms of the arrivals at $\mathrm{Hi}$-net have high $\mathrm{S} / \mathrm{N}$ ratios, and their waveforms are quite similar to those of direct $\mathrm{P}$

Table 1 Event locations

\begin{tabular}{|c|c|c|c|c|c|c|c|}
\hline Event & $\mathrm{MM} / \mathrm{DD} / \mathrm{YY}$ & Hour:minute & ${ }^{\circ} \mathrm{S}$ & ${ }^{\circ} \mathrm{W}$ & $h(\mathrm{~km})$ & $m_{b}$ & P-pP \\
\hline EV1 & 09/08/1996 & $11: 34$ & 19.759 & 179.211 & 678 & 5.6 & 139.9 \\
\hline EV2 & 09/08/1996 & $11: 42$ & 19.904 & 179.151 & 677 & 5.6 & 139.7 \\
\hline EV3 & 03/01/2000 & $04: 21$ & 19.149 & 179.315 & 671 & 5.8 & 138.7 \\
\hline EV4 & 03/01/2000 & $04: 46$ & 19.170 & 179.424 & 670 & 5.6 & 138.6 \\
\hline EV5 & $09 / 02 / 2000$ & $17: 02$ & 19.995 & 179.222 & 675 & 6.0 & 139.7 \\
\hline EV6 & $01 / 11 / 2004$ & 09:29 & 20.237 & 179.221 & 669 & 5.3 & 138.7 \\
\hline EV7 & $06 / 11 / 2006$ & 05:46 & 20.776 & 179.264 & 658 & 5.9 & 137.3 \\
\hline EV8 & 05/06/2007 & $21: 11$ & 19.548 & 179.460 & 673 & 6.5 & 139.2 \\
\hline EV9 & 05/06/2007 & $22: 01$ & 19.486 & 179.418 & 675 & 6.1 & 139.5 \\
\hline EV10 & 05/07/2007 & $00: 24$ & 19.240 & 179.515 & 670 & 5.6 & 138.7 \\
\hline EV11 & 05/13/2007 & $11: 26$ & 19.621 & 179.494 & 669 & 5.8 & 138.5 \\
\hline EV12 & 04/16/2008 & $22: 59$ & 19.509 & 179.389 & 668 & 4.7 & 138.4 \\
\hline EV13 & 01/07/2009 & $16: 25$ & 20.839 & 179.328 & 661 & 5.3 & 137.9 \\
\hline EV14 & $01 / 24 / 2009$ & 09:01 & 19.850 & 178.990 & 669 & 5.6 & 138.5 \\
\hline
\end{tabular}


EV9 Hi-net : $d=69.0: h=675.0: 1$.-th rel. to $P$ ak135

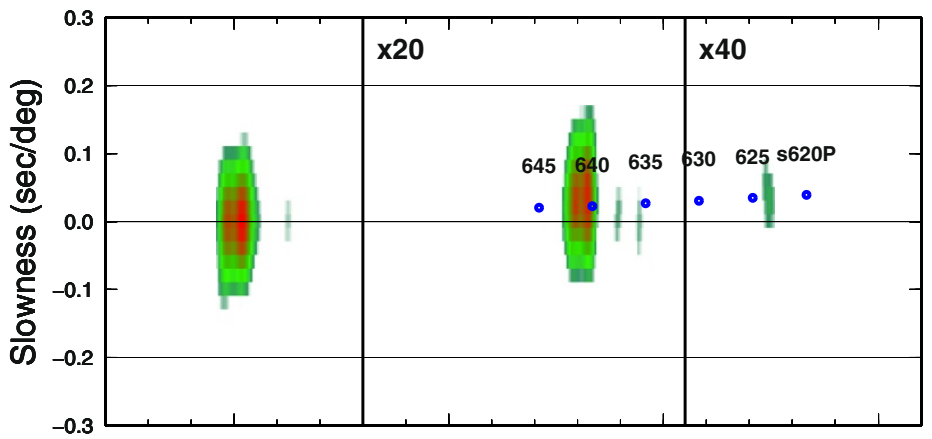

EV8 Hi-net : $d=69.7: h=673.0: 1$.-th rel. to $P$ ak135

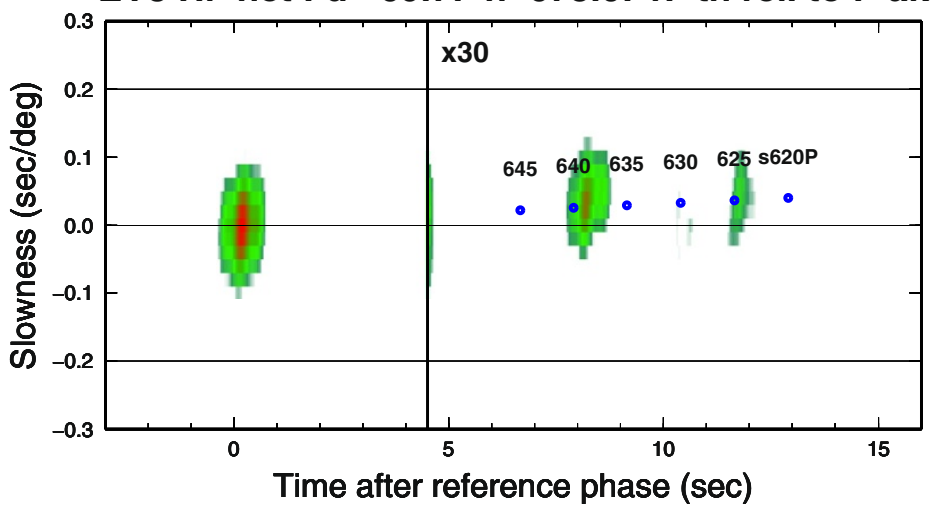

Figure 2 Examples of slant stack vespagrams for selected events. (Top) EV9 (Table 1) recorded at the Hi-net. Seismograms are phase-weight stacked with $n=1$ (Schimmel and Paulssen 1997), and the color shows the stacked intensity (the strongest signals are red). The horizontal axis is the delay time $(\Delta t)$ in seconds after the first peak of the direct $P$ wave. The vertical axis is the slowness relative to the direct $P$ wave $(\Delta p)$ in seconds per degree. Arrival of the $X$ phase (s-to-P reflected wave at horizontal interface above the foci) is seen near $8 \mathrm{~s}$ after $P$ ( $\mathrm{s} 641 \mathrm{P}$, Table 1 ). The predictions of s-to-P based on ak135 are marked with blue dots for every $5 \mathrm{~km}$ of interface depth. The stack outputs between 3 to $10.5 \mathrm{~s}$ after $\mathrm{P}$ are magnified 20 times, while those after $10.5 \mathrm{~s}$ are magnified 40 times. (Bottom) Same as the top panel, for EV8, showing the arrival of s639P (Table 1). The outputs after $4.5 \mathrm{~s}$ after $\mathrm{P}$ are magnified 30 times.

Table 2 Measurements for $X$ and $Y$ phases

\begin{tabular}{|c|c|c|c|c|c|c|c|c|}
\hline \multirow[b]{2}{*}{ Event/array } & \multirow[b]{2}{*}{$h(\mathrm{~km})$} & \multicolumn{3}{|c|}{$x$} & \multirow[b]{2}{*}{$A$} & \multicolumn{3}{|c|}{$Y$} \\
\hline & & $\Delta t(s)$ & $\Delta p$ & Depth & & $\Delta t(s)$ & $\Delta p$ & Depth \\
\hline EV2/UW & 677 & 8.6 & +0.02 & 642 & 0.05 & - & - & - \\
\hline EV4/JA & 670 & 7.1 & +0.06 & 640 & 0.04 & 10.4 & +0.03 & 627 \\
\hline EV6/UW & 669 & 6.7 & -0.01 & 642 & 0.07 & 10.2 & +0.02 & 629 \\
\hline EV8/HI & 673 & 8.0 & +0.03 & 639 & +0.10 & 11.6 & +0.02 & 627 \\
\hline EV8/UW & 673 & 9.6 & 0.00 & 635 & 0.04 & - & - & - \\
\hline EV9/HI & 675 & 8.1 & +0.03 & 641 & -0.14 & 12.3 & +0.03 & 624 \\
\hline EV10/HI & 670 & 7.5 & +0.02 & 639 & -0.07 & 11.2 & +0.02 & 624 \\
\hline EV11/HI & 669 & 7.6 & +0.02 & 638 & -0.10 & 10.0 & +0.0 & 628 \\
\hline EV13/HI & 661 & 4.8 & 0.0 & 642 & 0.03 & 9.1 & +0.02 & 624 \\
\hline
\end{tabular}

$A$ is the amplitude of the $\mathrm{X}$ phase relative to the direct $\mathrm{P}$ wave. Plus or minus signs are shown for $A$ only when the polarities are certain. $\mathrm{HI}, \mathrm{JA}$, and $\mathrm{UW}$ indicate Hi-net, $J$-array, and University of Washington array, respectively. 


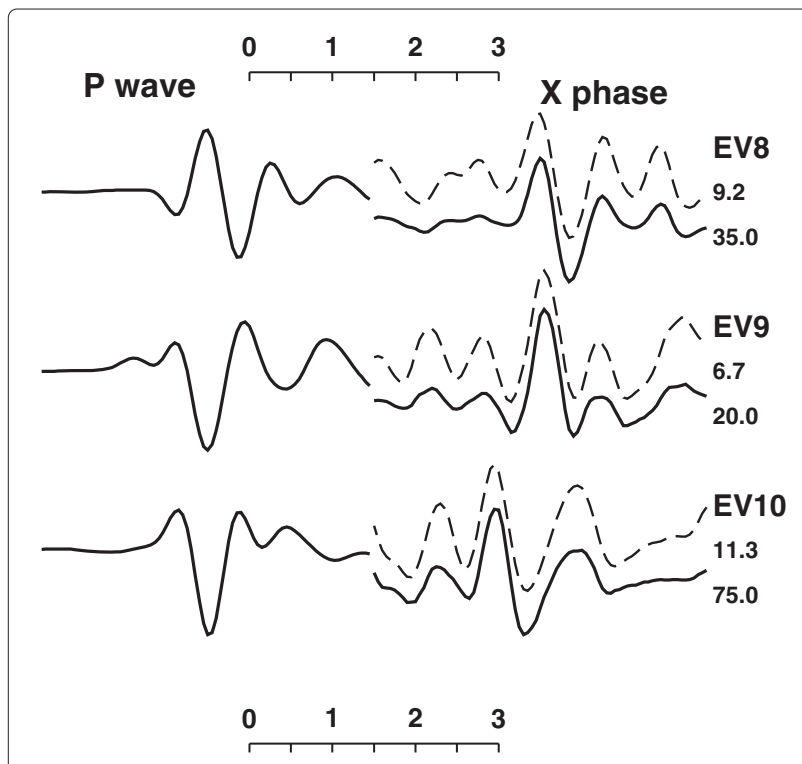

Figure 3 Examples of stacked waveforms for the direct $P$ waves and s-to-P waves at Moho observed at Hi-net. Stacked waveforms for the direct $P$ waves (left traces) and the s-to-P waves at Moho ('X phase', right traces) observed at Hi-net. Stacking is performed over the entire Hi-net with corresponding slowness values. The seismograms for the $X$ phases are linearly stacked (dashed lines) or phase-weighted stacked (solid lines). Each trace is normalized to its maximum peak-to-peak amplitude. The stacked waveforms of the $X$ phase are magnified relative to the stacked $P$ wave, and the magnification factor for each trace is shown below the event name. When phase-weighted stacked, the amplitudes of weaker anomalous arrivals are reduced compared to those of the linearly stacked waveforms. Note that the polarities of the X phase of EV9 and EV10 are flipped relative to the $\mathrm{P}$ waves that are initially positively polarized, while the X phase polarity of EV 8 is the same as the P wave that is negatively polarized.

arrivals. However, the polarities relative to $\mathrm{P}$ are different between EV8 and the other two events (Figure 3). According to their focal mechanisms and the $\mathrm{P}$ wave polarities observed at Hi-net, if the $\mathrm{S}$ wave speed (Vs) decreases upward across the interface, an s-to-P wave reflected at a horizontal interface immediately above the foci should have the same (EV8) or flipped (EV9 and EV10) polarity compared with the direct $\mathrm{P}$. This is consistent with what is observed for the three events (Figure 3) and thus strengthens the interpretation that the arrivals are s-to$P$ reflected waves. Based on the observed amplitudes of the arrivals relative to direct $\mathrm{P}$ (Table 2), we estimate the jump of seismic speeds across the interface. The data set is most sensitive to the Vs contrast, so we assume that the $\mathrm{Vp}$ anomaly scales with the Vs anomaly. We find that the Vs drops upward from the inside to the outside of the horizontally lying slab by a few percent (approximately $3 \%$ ) when the interface is a first-order discontinuity, although the estimate carries substantial uncertainty due to the limited accuracy of the focal mechanisms. The observations of the interface location and the sense of anomaly indicate that the interface represents the Moho of former oceanic crust attached to the subducting Tonga slab.

There is also a weaker later arrival nearly $4 \mathrm{~s}$ after the $\mathrm{s}$-to-P reflection at the Moho (called ' $\mathrm{Y}$ phase'), which also tends to show positive slowness relative to $\mathrm{P}$ (Table 2; Figure 2). We interpret this also to be s-to-P reflections from another interface above the Moho, which would represent the surface of the former oceanic crust. Although the polarity of this weaker arrival has not been constrained, the vertical distance between the two interfaces $(14 \pm 2 \mathrm{~km})$ is determined using $\Delta \mathrm{t}$ (Table 2).

\section{Thermal structure of the Tonga slab}

The Tonga slab is one of the coldest slabs, with a $\Phi$ of about $9,000 \mathrm{~km}$ around the study area. In order to determine the detailed thermal structure of the Tonga slab, we calculate the stream function and temperature fields associated with the subduction of the Pacific Plate beneath the Australian Plate by numerically simulating temperature and mantle flow in a 2-D box model (Yoshioka and Sanshadokoro 2002) (Figure 4a). As the initial condition concerning mantle flow in the model, no flow condition is given, and mantle flow is entirely driven by the subduction of the Pacific Plate. As the initial condition for the temperature distribution in the model space, we use a layered thermal state of a cooling oceanic plate described by an error function. Heating due to adiabatic compression is taken into account in computing temperatures for depths below $150 \mathrm{~km}$, as is commonly performed (e.g., Torii and Yoshioka 2007). As the boundary condition for temperature, we assume that materials with this temperature profile for the oceanic Pacific Plate flow into the model domain from the side boundary (Figure 4a). Temperature at the model surface is fixed to $0^{\circ} \mathrm{C}$, and an adiabatic condition is given for the left and bottom boundaries (Figure 4a). Friction at the interface between the slab and the overriding continental plate is not included, but its effect on the slab temperature near the bottom of the upper mantle is negligible. Latent heat absorption associated with the phase transformations is not incorporated into the model. Latent heat absorption of post-spinel transformation reduces the temperature only slightly (Yoshioka et al. 1997). On the other hand, when the transformation from metastable olivine to either wadsleyite or ringwoodite occurs, latent heat release causes a temperature rise. The temperature increase is primarily dependent on where the phase transformation occurs. It would exceed $200^{\circ} \mathrm{C}$ when the transformation occurs immediately upstream of the foci (Kirby et al. 1996; Kubo et al. 2009) or would be less than $50^{\circ} \mathrm{C}$ for the transformation at a $450-\mathrm{km}$ depth, where the coldest temperature of the Tonga slab is approximately $600^{\circ} \mathrm{C}$. According to recent experimental studies, the latter case seems more 


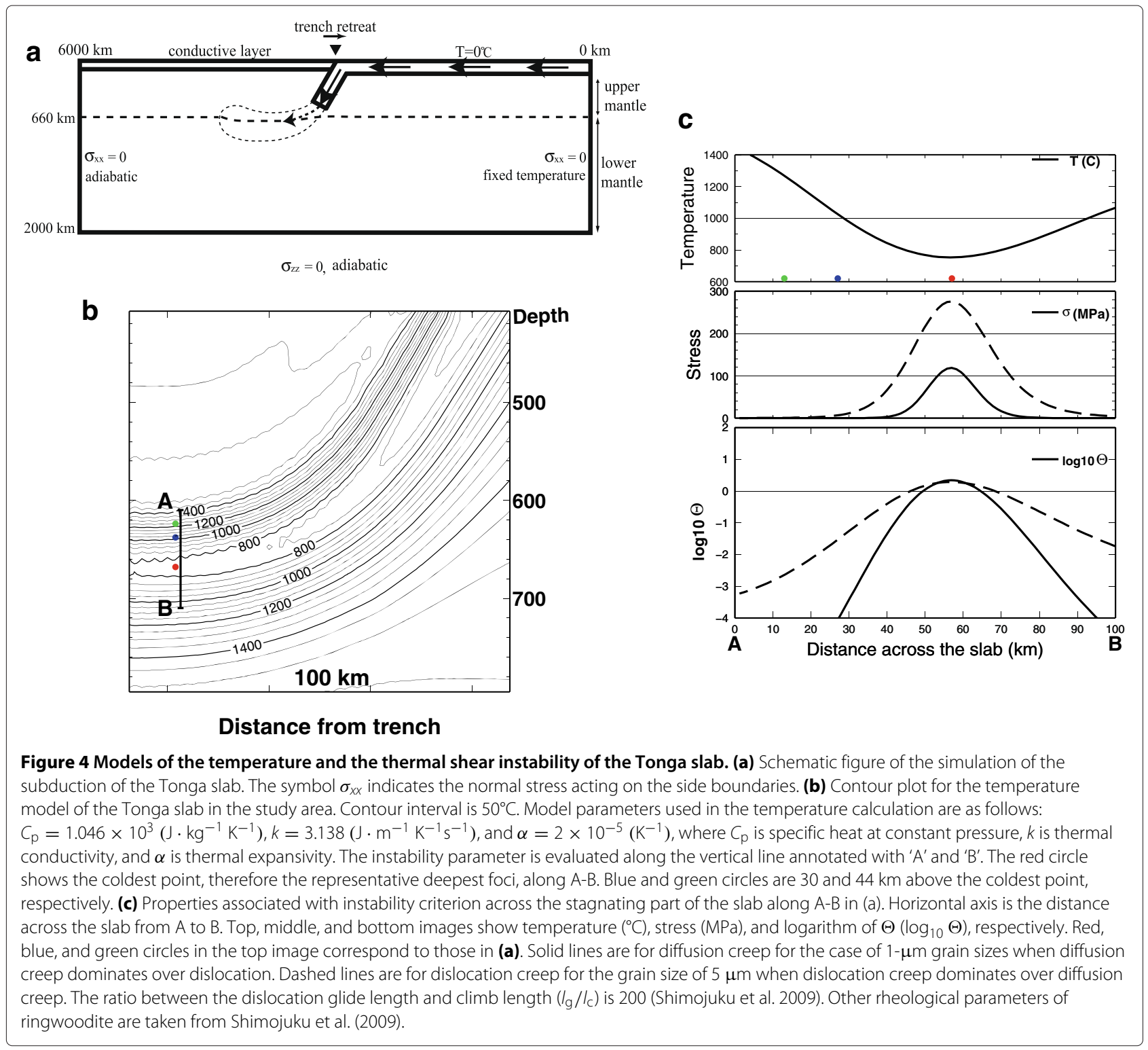

plausible (e.g., Perrillat et al. 2013). As there is no observational constraint on the metastable olivine wedge for the study region, further quantitative arguments about this effect seem inadequate.

For the region outside the slab, we solve the momentum equation expressed by the stream function and the energy equation simultaneously as a coupled problem using a 2-D finite difference method. The slab materials inside a prescribed guide are forced to descend kinematically, with a uniform velocity of $10 \mathrm{~cm} /$ year at the age about 100 Myr. The trench is kinematically rolled back by $5 \mathrm{~cm} /$ year (e.g., Heuret and Lallemand 2005; van der Hilst 1995), using the method described in Torii and Yoshioka (2007). The Clapeyron slope of the post-spinel transformation is $-2.0 \mathrm{MPa} / \mathrm{K}$ (Kaneshima et al. 2012).
We assume that mantle viscosity depends on temperature and depth for the calculation of the thermal structure (Christensen 1996; Kaneshima et al. 2012). The viscosity of the shallowest $300 \mathrm{~km}$ of the lower mantle is reduced to a quarter of that of the transition zone. A guide descending $60^{\circ}$ down to $500-\mathrm{km}$ depth is prescribed in order to model the flow which resembles the Tonga slab. Other details of the simulation are the same as those in Kaneshima et al. (2012).

We seek a transient temperature structure that resembles the overall shape of the slab imaged by tomography studies (Obayashi et al. 2006; van der Hilst 1995) and the deep seismicity in the study area (Figure 1b).

Figure $4 \mathrm{~b}$ shows the calculated temperature distribution at a time 20 Myr after the initiation of the subduction of 
the Pacific Plate, which adequately matches the shape of the Tonga slab. The model parameters used for obtaining the model are listed in the caption of Figure 4. It is possible to find different sets of dynamical parameters that fit the observations equally well, but our aim in performing the simulation is to present a model of a temperature field that is physically and tectonically feasible.

\section{Location of the former oceanic Moho relative to the deep earthquakes}

Deep earthquakes are often considered to occur around the coldest part of subducting slabs (Gorbatov and Kostoglodov 1997; Karato et al. 2001). The coldest slab temperature at $660-\mathrm{km}$ depth is approximately $750^{\circ} \mathrm{C}$ for the thermal parameter $\Phi$ of about $7,000 \mathrm{~km}$ (Karato et al. 2001), approximately $680^{\circ} \mathrm{C}$ for $\Phi$ approximately $14,000 \mathrm{~km}$ (Kubo et al. 2009), and approximately $700^{\circ} \mathrm{C}$ for $\Phi$ approximately 8,600 km (Bina and Kawakatsu 2010). Emmerson and McKenzie (2007) estimate the coldest temperature of the Tonga slab to be $681^{\circ} \mathrm{C}$ to $710^{\circ} \mathrm{C}$ using temperature-dependent thermal conductivity models. The temperature of the coldest portion at depths of 660 to $680 \mathrm{~km}$ in our model for the Tonga slab is slightly above $750^{\circ} \mathrm{C}$ (Figure 4) and is generally consistent with previous estimates.

Next, we evaluate the permissible range of temperature estimates. Thermal conductivity $(k)$ is obviously an influential parameter and is fixed at $3.138 \mathrm{~J} \cdot \mathrm{m}^{-1} \mathrm{~K}^{-1} \mathrm{~s}^{-1}$ in our simulations (Marton et al. 2005). As $k$ may decrease with temperature (Emmerson and McKenzie 2007), we investigate a range of $k$ from 2.9 to $3.2 \mathrm{~J} \cdot \mathrm{m}^{-1} \mathrm{~K}^{-1} \mathrm{~s}^{-1}$. We also vary the age of the Pacific Plate within a range from 90 to 120 Myr. The results show that the temperature at the coldest part of the Tonga slab could differ from the current estimate by about $20^{\circ} \mathrm{C}$. The value of $k$ is constant in our simulations. If its temperature dependency is considered, the difference could be larger (Emmerson and McKenzie 2007).

If we assume that the deepest earthquakes in Tonga occur near the coldest portion of the slab, the location of the seismically detected Moho relative to the events (30 $\mathrm{km}$ above the foci) indicates that the temperature of the base of the former crust is nearly $1,050^{\circ} \mathrm{C}$, according to the calculated thermal model (Figure $4 \mathrm{~b}$ ). Thus, the temperature $14 \mathrm{~km}$ below the slab surface is approximately $400^{\circ} \mathrm{C}$ colder than the surrounding mantle (Figure $4 \mathrm{~b}$ ), which generally agrees with previous studies (e.g., Karato et al. 2001; Bina and Kawakatsu 2010). We thus claim that the location of the Moho is quite reasonable. Combined with the consistency among previous tomography images, the deep seismicity (Figure 1b), the dynamically plausible temperature structure (Figure $4 \mathrm{~b}$ ), and the relative location of the deepest earthquakes and the Moho provide strong support for the model that deep earthquakes occur only below a certain temperature that is near $750^{\circ} \mathrm{C}$.

The estimated maximum temperature for deep seismicity falls within the range obtained by Gorbatov and Kostoglodov (1997) (approximately $600^{\circ} \mathrm{C}$ to $800^{\circ} \mathrm{C}$ ) but is higher than for the Marianas $\left(550^{\circ} \mathrm{C}\right.$; Kubo et al. 2009) and the higher estimate for Tonga $\left(710^{\circ} \mathrm{C}\right.$; Emmerson and McKenzie 2007). The large difference between the temperatures for the Marianas and Tonga may be caused by the fact that the temperature for the Marianas indicates the temperature at which metastable olivine disappears and does not strictly represent the limiting temperature of deep seismicity.

The upper bound temperature we estimated may carry an uncertainty on the order of $50^{\circ} \mathrm{C}$, since it depends on the tectonic parameters of the slab and the properties of the slab materials as described above. However, the narrow range of focal depths of the deepest earthquakes (approximately $20 \mathrm{~km}$ ) indicates that the temperature range that encompasses the seismogenic zone is as narrow as $50^{\circ} \mathrm{C}$. Therefore, the presence of a stringent upper limit of temperature for the deepest seismogenesis is robust.

\section{Discussion}

The mechanism of deep earthquakes is still controversial. The postulated mechanisms include transformational faulting of olivine (e.g., Kirby et al. 1996), adiabatic shear (plastic) instability (e.g., Karato et al. 2001), and embrittlement due to dehydration of hydrous minerals (Meade and Jeanloz 1991). As for dehydration embrittlement, the deepest earthquakes at the Marianas occur mainly inside the metastable olivine wedge that is inferred to be very dry (Kubo et al. 2009). Green et al. (2010) also claim that subducting slabs are almost dry below $400 \mathrm{~km}$. We have shown in the last section that the deepest seismicity is strictly controlled by temperature. There is no dehydration reaction that is sensitive to temperature under the low-temperature conditions relevant to a cold slab like the Tonga slab, according to the phase diagram of hydrated minerals associated with the slab (Ohtani 2005; Komabayashi et al. 2004). Dehydration embrittlement can thus be eliminated.

For both the transformational faulting and shear instability mechanisms, faulting is most likely to occur near the coldest places inside slabs. Therefore, the thermal control we have shown seems compatible with these two mechanisms.

Transformational faulting requires the presence of metastable olivine around the deepest foci, which has not been proved for the study region. It also means that the observed seismicity reflects the disappearance of metastable olivine at a distance of about $1,000 \mathrm{~km}$ from the trench along the slab. According to recent 
experimental studies (e.g., Perrillat et al. 2013; Du Frane et al. 2013), the estimated temperature at the foci (approximately $750^{\circ} \mathrm{C}$ ) seems too high for a substantial volume of metastable olivine to persist down to this distance from the trench, unless the slab is extremely dry (the $\mathrm{H}_{2} \mathrm{O}$ content is much less than $70 \mathrm{ppm}$ ).

In the absence of metastable olivine, the rheology of the slab near the foci is controlled by the rheology of ringwoodite, for which the expected deformation style would be either diffusion creep or dislocation creep, depending primarily on the grain size (e.g., Shimojuku et al. 2009). We consider whether thermal shear instability readily occurs under the temperature, pressure, and strain rate of the slab model near the deepest foci (Figure 4b). A catastrophic plastic slip occurs when the strain softening effect due to temperature rise following the deformation exceeds the strain hardening effect. The more the stress is exerted and the cooler the temperature, the more likely the instability is to occur. The criterion for instability is expressed as $\Theta \equiv-\left(\frac{\partial \sigma}{\partial T}\right)_{\epsilon, \dot{\epsilon}} \frac{\kappa}{a C \rho}>1$, where $\sigma$, $C, \rho, \kappa$, and $a$, are differential stress, specific heat, density, fraction of heat retained in a slipped region during the slip, and strain hardening factor, respectively (Hobbs and Ord 1988; Karato et al. 2001). We evaluate $\left(\frac{\partial \sigma}{\partial T}\right)_{\epsilon, \dot{\epsilon}}$, and therefore $\Theta$, by assuming quasi-steady state plastic flow laws for our slab model (Figure 4c; see the caption for the parameter values). The strain rate is assumed to be $5 \times 10^{-15} \mathrm{~s}^{-1}$ uniformly, but its effects are small. The strain hardening constant for the creep, $a \equiv \frac{1}{\sigma}\left(\frac{\partial \sigma}{\partial \epsilon}\right)_{\dot{\epsilon}, T}$, is set to 0.5 following Hobbs and Ord (1988). The heat fraction $\kappa$ is 1 . According to the profiles of $\Theta$ across the slab along the line A-B in Figure 4b (bottom image of Figure 4c), for diffusion creep that is dominant when the grain size is $1 \mu \mathrm{m}$, instability can only occur approximately $15 \mathrm{~km}$ around the coldest part of the slab (solid lines in Figure 4c). This is consistent with the observations (Figure 1b). When the grain size is larger, say, $\geq 5$ $\mu \mathrm{m}$, dislocation creep dominates, but instability is still possible approximately $25 \mathrm{~km}$ around the coldest temperature (dashed lines in Figure 4c). Thus, thermal shear instability adequately explains the essential features of the the observation with the currently most acceptable rheological parameters.

In this study, we consider transformational faulting and thermal shear instability separately. If metastable olivine persists to the foci and the two mechanisms are concomitant, latent heat release due to the transformation increases the temperature, weakens the surrounding rocks, and enhances the instability. The stress regime around the deepest foci of this study, estimated by the focal mechanisms, is lateral compression parallel to WNW-ESE, nearly parallel to the direction of the maximum dip of the slab. The stress regime obtained by our simulation is consistent with the observation.
Competing interests

The authors declare that they have no competing interests.

\section{Authors' contributions}

SK carried out the seismological studies, evaluated the instability parameters, and wrote the manuscript. SY performed the numerical simulations for the temperature field of the Tonga slab. Both authors read and approved the final manuscript.

\section{Acknowledgements}

We owe a debt of gratitude to IRIS DMC, University of Washington, NIED at Tsukuba Japan, and J-array center, ERI, for supplying the waveform data. GMT (Wessel and Smith 1995) was used to draw all the figures. We thank Tomoaki Kubo for valuable discussions. Comments by two anonymous reviewers were useful for improving this paper.

\section{Author details}

${ }^{1}$ Department of Earth and Planetary Sciences, Faculty of Science, Kyushu University, Hakozaki, Higashi-ku, Fukuoka 812-8581, Japan. ${ }^{2}$ Research Center for Urban Safety and Security, Kobe University, Kobe 657-8501, Japan.

Received: 8 April 2014 Accepted: 1 October 2014

Published online: 15 October 2014

\section{References}

Bina CR, Kawakatsu H (2010) Buoyancy, bending, and seismic visibility in deep slab stagnation. Phys Earth Planet Inter 183:330-340

Christensen UR (1996) The influence of trench migration on slab penetration into the lower mantle. Earth Planet Sci Lett 14:27-39

Deal MM, Nolet G, van der Hilst RD (1999) Slab temperature and thickness from seismic tomography, 1. Method and application to Tonga. J Geophys Res 104:28789-28802

Du Frane WL, Sharp TG, Mosenfelder JL, Leinenweber K (2013) Ringwoodite growth rates from olivine with $\sim 75$ ppmw $\mathrm{H}_{2} \mathrm{O}$ : metastable olivine must be nearly anhydrous to exist in the mantle transition zone. Phys Earth Planet Inter 219:1-10

Emmerson B, McKenzie D (2007) Thermal structure and seismicity of subducting lithosphere. Phys Earth Planet Inter 163:191-208

Gorbatov A, Kostoglodov V (1997) Maximum depth of seismicity and thermal parameter of the subducting slab: general empirical relation and its application. Tectonophysics 277:165-187

Green HW, Cheng WP, Brudzinski MR (2010) Seismic evidence of negligible water carried below 400-km depth in subducting lithosphere. Nature 467:828-831

Gudmundsson O, Sambridge MJ (1998) A regionalized upper mantle (RUM) seismic model. J Geopys Res 103:7127-7136

Helffrich G, Stein S, Wood BJ (1989) Subduction zone thermal structure and mineralogy and their relationship to seismic wave reflections and conversions at the slab/mantle interface. J Geophys Res 94:753-763

Heuret A, Lallemand S (2005) Plate motions, slab dynamics and back-arc deformation. Phys Earth Planet Inter 149:31-51

Hobbs BE, Ord A (1988) Plastic instability: implications for the origin of intermediate and deep earthquakes. J Geophys Res 93:10521-10540

Kaneshima S, Helffrich G (1999) Dipping low-velocity layer in the mid-lower mantle: evidence for geochemical heterogeneity. Science 283:1888-1891

Kaneshima S, Helffrich G (2010) Small scale heterogeneity in the mid-lower mantle beneath the circum-Pacific area. Phys Earth Planet Inter 183:91-103

Kaneshima S, Okamoto T, Takenaka H (2007) Evidence for a metastable olivine wedge inside the subducted Mariana slab. Earth Planet Sci Lett 258:219-227

Kaneshima S, Kubo T, Yoshioka S (2012) Geophysical and mineralogical constraints on the post-spinel transformation for the Tonga slab. Phys Earth Planet Inter 196-197:23-31

Karato S (1997) On the separation of crustal component from subducted oceanic lithosphere near the $660 \mathrm{~km}$ discontinuity. Phys Earth Planet Inter 99:103-111

Karato S, Riedel MR, Yuen DA (2001) Rheological structure and deformation of subducted slabs in the mantle transition zone: implications for mantle circulation and deep earthquakes. Phys Earth Planet Inter 127:83-108

Kennett BLN, Engdahl ER, Buland R (1995) Constraints on seismic velocities in the Earth from travel times. Geophys J Int 122:108-124 
Kirby SH, Stein S, Okal EA, Rubie DC (1996) Metastable mantle phase transformations and deep earthquakes in subducting oceanic lithosphere. Rev Geophys 34:261-306

Komabayashi T, Omori S, Maruyama S (2004) Petrogenetic grid in the system $\mathrm{MgO}-\mathrm{SiO}_{2}-\mathrm{H}_{2} \mathrm{O}$ up to $30 \mathrm{GPa}, 1600^{\circ}$ : applications to hydrous peridotite subducting into the Earth's deep interior. J Geophys Res 109:B04206. doi:10.1029/2003JB002651

Kubo T, Kaneshima S, Torii Y, Yoshioka S (2009) Seismological and experimental constraints on metastable phase transformations and rheology of the Mariana slab. Earth Planet Sci Lett 287:12-23

Marton FC, Shankland TJ, Rubie DC, Xu Y (2005) Effects of variable thermal conductivity on the mineralogy of subducting slabs and implications for mechanisms of deep earthquakes. Phys Earth Planet Inter 149:53-64

Meade C, Jeanloz R (1991) Deep-focus earthquakes and recycling of water into the Earth's mantle. Science 252:68-72

Nakanishi I (1980) Precursors to ScS phases and dipping interface in the upper mantle beneath southwestern Japan. Tectonophysics 69:1-35

Obayashi M, Sugioka H, Yoshimitsu J, Fukao Y (2006) High temperature anomalies oceanward of subducting slabs at the $410-\mathrm{km}$ discontinuity. Earth Planet Sci Lett 243:149-158

Ohtani E (2005) Recent progress in experimental mineral physics: phase relations of hydrous systems and the role of water in slab dynamics. In: van der Hilst R (ed). Earth's deep mantle: structure, composition, and evolution. AGU, Washington, D.C. pp 321-334

Perrillat JP, Daniel I, Bolfan-Casanova N, Chollet M, Morard G, Mezouar M (2013) Mechanism and kinetics of $\alpha-\beta$ transition in San Carlos olivine $\mathrm{Mg}_{1.8} \mathrm{Fe}_{0.2} \mathrm{SiO}_{4}$. J Geophys Res 118:110-119

Schimmel M, Paulssen H (1997) Noise reduction and detection of weak, coherent signals through phase-weighted stacks. Geophys J Int 130:497-505

Shimojuku A, Kubo T, Ohtani E, Nakamura T, Okazaki R, Dohmen R, Chakraborty $\mathrm{S}$ (2009) $\mathrm{Si}$ and $\mathrm{O}$ diffusion in $(\mathrm{Mg}, \mathrm{Fe})_{2} \mathrm{SiO}_{4}$ wadsleyite and ringwoodite and its implications for rheology of the mantle transition zone. Earth Planet Sci Lett 445:200-209

Torii Y, Yoshioka S (2007) Physical conditions producing slab stagnation: constraints of the Clapeyron slope, mantle viscosity, trench retreat, and dip angles. Tectonophysics 445:200-209

van der Hilst R (1995) Complex morphology of subducted lithosphere in the mantle beneath the Tonga trench. Nature 374:154-157

Wessel P, Smith WH (1995) New version of generic mapping tools. EOS Trans AGU Electron Suppl 79:579

Wiens DA (2001) Seismological constraints on the mechanism of deep earthquakes: temperature dependence of deep earthquake source properties. Phys Earth Planet Inter 127:145-163

Yoshioka S, Daessler R, Yuen DA (1997) Stress fields associated with metastable phase transitions in descending slabs and deep-focus earthquakes. Phys Earth Planet Inter 104:345-361

Yoshioka S, Sanshadokoro H (2002) Numerical simulations of deformation and dynamics of horizontally lying slabs. Geophys J Int 151:69-82

doi:10.1186/s40623-014-0138-2

Cite this article as: Kaneshima and Yoshioka: Dominant role of temperature on deep earthquake mechanics for the Tonga slab near the bottom of the upper mantle. Earth, Planets and Space 2014 66:138.

\section{Submit your manuscript to a SpringerOpen ${ }^{\odot}$ journal and benefit from:}

- Convenient online submission

Rigorous peer review

- Immediate publication on acceptance

- Open access: articles freely available online

- High visibility within the field

- Retaining the copyright to your article

Submit your next manuscript at $\boldsymbol{\triangleright}$ springeropen.com 